\title{
Investigation into Failure Analysis of Friction Rollers on Rice Milling Machine at Igbemo Ekiti
}

\author{
Momoh, J. J \\ Department of Mechanical Engineering \\ The Federal Polytechnic, Ado-Ekiti \\ Nigeria
}

\author{
Olakolegan, O. D \\ Department of Mechanical Engineering \\ The Federal Polytechnic, Ado-Ekiti \\ Nigeria
}

\author{
Ukachi, P. A \\ Department of Mechanical Engineering \\ The Federal Polytechnic, Ado-Ekiti \\ Nigeria
}

\begin{abstract}
The failure analysis of a worn friction roller in a rice hulling machine was studied. Two major wear mechanisms such as abrasion and erosion were identified in the process of removal of husk from rice paddy. Micro-structural analysis, fractography and spectrometry methods were employed in the failure analysis. The optical microscope was used to obtain the pealitic and ferritic structure of the friction roller material. Physical observation and mechanical property tests of the friction roller revealed the evolution of fracture. The chemical composition of the material showed that it contains certain alloying elements, such as: Carbon, Manganese, Sulphur, Silicon, etc. According to the result obtained and considering the available information, it was concluded that the friction roller fractured in a brittle mode, the presence of pearlite, ferrite in the grain boundaries are not the same which contributed to the failure of the friction roller.
\end{abstract}

\section{Keywords-Friction, Roller, Assessment, Rice husk}

\section{INTRODUCTION}

Rice (Oryza sativa L.) is a staple food of over half the world's people and is grown on approximately 146 million hectares, more than 10 percent of total available land. Total world production is about 535 million tons of unmilled or rough rice (paddy). Ninety seven percent ( 97 percent) of the world's rice is grown by less developed countries, mostly in Asia. China and India produce about 55 percent of the total crop [1]. It has supported a greater number of people for a longer period of time than any other crop since it was domesticated between 8,000 to 10,000 years ago [2]. At present, rice is the staple food for more people than wheat [3]. Today, it is an increasingly important crop in Nigeria. It is relatively easy to produce and is grown for sale and for home consumption. It is the main crop in Igbemo-Ekiti, Ekiti State, Nigeria, yet the full economic effect of its production is yet to be determined [4]. Ekiti State is one of the leading 13 rice producing states in Nigeria, and was leading in the first republic with the production of Igbemo rice [5]. The major problem with the domestic output of rice in Nigeria is the poor operational techniques of processing rice which often aid low production. Efforts of government through the Agricultural Development Project (ADP) to improve rice processing operational techniques especially in Ekiti State have appeared ineffective [6].
This work is a contribution to efforts aimed at the development of wear resistance friction roller in a rice hulling machine used by Igbemo-Ekiti rice farmer with high performance indices at reduced cost. To typical Igbemo-Ekiti rice farmer, the milling yield and quality of rice is dependent on the quality of the paddy, the milling equipment used and the skill of the rice milling machine operator].

\section{RICE MILLING SYSTEM}

Milling is a crucial step in post-production of rice. The basic objective of a rice milling system is to remove the husk and the bran layers, and produce an edible, white rice kernel that is sufficiently milled and free of impurities. Depending on the requirements of the customer, the rice should have a minimum of broken kernels [7].

As early as 1500 BC, West African women were processing rice using a hand-pounding mortar and pestle to separate the indigestible hulls from the rice [8]. Pounding rice required great skill to insure that the majority of the end product is clean whole grains rather than partially broken or small broken pieces of rice.

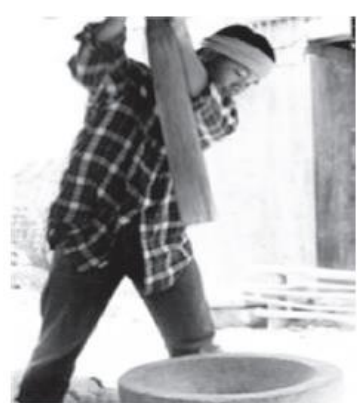

Fig. 1. Pounding rice with Mortar and Pestle

Hand pounding of paddy in a mortar with a pestle is still practiced in some remote areas. Pounding the paddy induces upward and downward forces on grain against grain that removes the husk and some bran layers. The pounding also results in a high percentage of broken kernels.

One of the most popular single pass rice mills is the steel huller which is popular for milling parboiled rice in IgbemoEkiti. This mill is a steel friction type mill and uses very high pressure to remove the hull and polish the grain. In removing the husk, the husk layer is removed from the paddy by friction and the process is called de-husking or de-hulling. De-husking that is traditionally done using mortar and pestles are now 
mechanized with the use of modern rice mills by passing the paddy grains between two abrasive surfaces that are moving at different speeds shown in Figure 2.

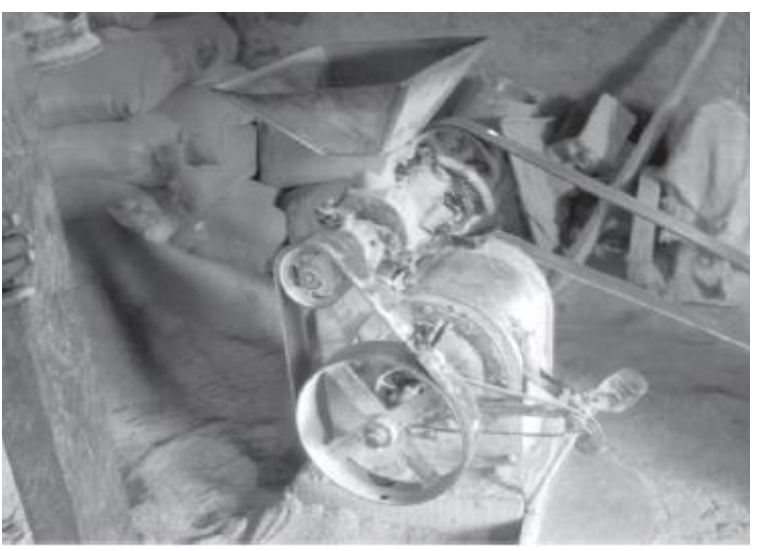

Fig. 2. Igbemo-Ekiti Rice Milling Machine

The investigation of failures which caused the breakdown of the roller may be caused by use of inadequate materials. To investigate the failure of a friction roller in a rice milling machine, the difficulty caused by tribological defect which often occurs during operation of rice huller, why the persistence in failure and to solve the problem of friction and wear.

\section{METHODOLOGY}

A rice huller with ribbed surface was selected, spark (at the USteel company, Lagos) using spectrometric analyzer to determine the chemistry. It was thereafter machined to tensile configuration of an average gauge length and diameter of $57 \mathrm{~mm}$ and $5 \mathrm{~mm}$ respectively; impact samples was also machined following ASTM standard [9] while pieces were also cut for hardness and microstructural examinations.

\section{RESULTS AND DISCUSSION}

Table 1 below shows the chemical composition of the specimen, it was found to be medium carbon steel with $0.35 \%$ carbon content which is a major factor for the significant high hardness and impact values (Table 2). Prior to the hardness test, the samples were subjected to grinding using emery papers of various grits (between $60-2400 \mathrm{um}$ ) and subsequently polished in a superfine polishing cloth to enhance a mirror-like surface on the samples, Multiple hardness tests were performed on each sample and the average value taken as a measure of the hardness of the specimen. The result indicates the extent of wear resistance of huller while in operation.

Table 1a: Spectrometric analysis of a rice huller roller

\begin{tabular}{|l|c|c|c|c|c|c|}
\hline Elements & $\mathrm{C}$ & $\mathrm{Mn}$ & $\mathrm{S}$ & $\mathrm{P}$ & $\mathrm{Si}$ & $\mathrm{Fe}$ \\
\hline Composition & 0.35 & 0.823 & 0.05 & 0.034 & 0.17 & Bal. \\
\hline
\end{tabular}

Table 1b: SAE No.4037 Alloy Steel Chemical Composition (LIQUIDE)

\begin{tabular}{|l|c|c|c|c|c|c|}
\hline Elements & $\mathrm{C}$ & $\mathrm{Mn}$ & $\mathrm{S}$ & $\mathrm{P}$ & $\mathrm{Si}$ & $\mathrm{Fe}$ \\
\hline Composition & $\begin{array}{c}0.35- \\
0.40\end{array}$ & $\begin{array}{c}0.70- \\
0.90\end{array}$ & 0.04 & 0.035 & $\begin{array}{c}0.15- \\
0.35\end{array}$ & Bal. \\
\hline
\end{tabular}

Table 2a: Hardness and impact strength values of a rice huller roller

\begin{tabular}{|c|c|c|}
\hline Samples & Micro-hardness value (HV) & Impact Strength (J) \\
\hline Steel & 180.7 & 43.5 \\
\hline
\end{tabular}

Table 2b: Limit of the hardness and impact strength according to SAE DIN 1.1186

\begin{tabular}{|c|c|c|}
\hline Samples & Micro-hardness value (HV) & Impact Strength (J) \\
\hline Steel & 149.8 & 44.3 \\
\hline
\end{tabular}

Figure 3 shows the variation of engineering stress to strain of a rice huller which has been characterized and determined to be of medium carbon composition. It was observed to possess a high ultimate tensile stress value of $452.9 \mathrm{~N} / \mathrm{mm} 2$ and $0.2 \%$ offset proof strength of $412.9 \mathrm{~N} / \mathrm{mm} 2$, this indicate the endurance limit of the material (MCS) before yielding to external stress. The result also shows that the material has exhibited an extension of $3.67 \%$ of the original length before failure.

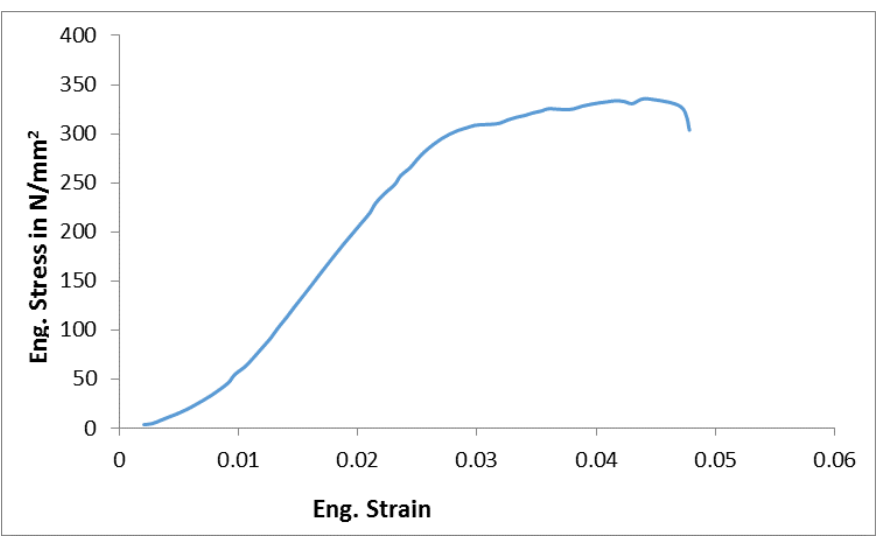

Fig. 3: Variation of Engineering Stress to Strain of Rice Huller

Plates 1 and 2 are micrographs showing the internal structure of the steel. It was captured using daheng software driven metallurgical microscope. Prior to the capture, the as received sample was grinded to a very smooth surface using silicon abrasives of different grits used sequentially from 60um - 2400um. It was subsequently polished on a polishing machine with a superfine polishing cloth to enhance the mirrorlike surface required for the microscope view. It was finally etched with a corresponding etchant ( $2 \%$ Nital solution) before viewing and capturing. From the result, it can be observed that a distinct phases of soft and ductile ferrite, and hard pearlitic phase was formed with a high volume percent of the dark phase indicating a dominating pearlite phase which contain more of the carbon content thereby enhancing the significantly high Ultimate Tensile Strength (UTS), hardness values as shown earlier. The ferrite phase, on the other hand, explains the ductility of the material.

The dark spots, however, indicates that pitting corrosion has engulfed the specimen, as it was supplied in the used form. The indications of each of the phases are shown in plate 2 . 


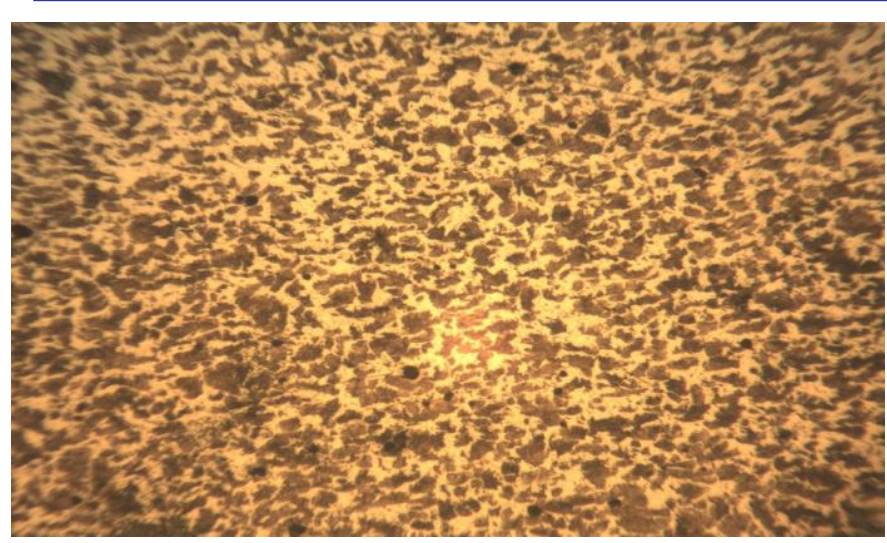

Plate 1: Micrograph of medium carbon steel captured at x200 magnification

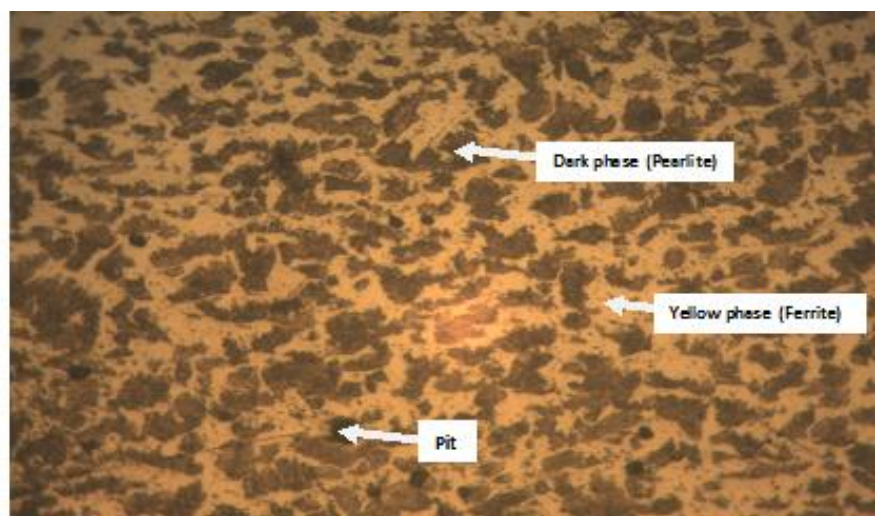

Plate 2: Micrograph of medium carbon steel captured at x400 magnification

\section{DISCUSSION}

The purpose of analyzing the chemical composition of the steel sample is to enable its classification to be made. Based on Table I, the steel can be classified as medium carbon steel, since both AISI and SAE classified steel whose carbon content ranges between $0.35-0.40 \%$, manganese content ranges between $0.70-0.90 \%$ medium carbon steel.

\section{CONCLUSION}

According to the result and considering the available information, the following conclusions were achieved: The friction roller fractured in a brittle mode, the presence of pearlite, ferrite in the grain boundaries are not the same which contributed to the failure of the friction roller.

The micro-structural heterogeneity is not the main cause of the fracture but it contributed to the occurrence of the failure, since it favored crack propagation. The design of the shaft contributed immensely to the failure of the friction roller.

Considering the fabrication defect the homogeneity of the microstructure could provide a longer life time for the friction roller. For further work to the range of wear, the roller should be subjected to Energy Dispersive X-Ray Spectroscopy (EDS) and Scanning Electron Microscopy (SEM). It is suggested that wear will be more appreciable if the focus is on the development of an improved understanding of the rice friction roller behavior, accurate wear processes that take place in the rice hulling machine. Also screen and the blade are to be investigated to know the rate of wear that take place in them.

\section{REFERENCES}

[1] IRRI. (1997). IRRI rice facts. The International Rice Research Institute (IRRI). Los Baños, Philippines.

[2] Greenland, D.J. 1997. The sustainability of rice farming. CAB International, Wallingford, UK, $273 \mathrm{p}$

[3] Evans, L.T. 1998. Feeding the ten billion: plants and population growth. Cambridge University Press, Cambridge, UK, 247 p.

[4] Basorun, J. O, (2010): Estimating the Geographical Influence of Rice Consumption from a Regional Agropole in Ekiti State, Nigeria, Journal of Food Distribution Research, Vol. 41, Issue 2.

[5] Gbenga, A (2014): Local rice: 'Nigeria to make N360bn, Ekiti N6bn', Vanguard Media Limited, Nigeria, Retrieved December 20, 2014 from http://www.vanguardngr.com/2014/04/local-ricenigeria-make-n360bnekitin6bn/\#sthash.cbdSJjW8.dpuf

[6] Basorun, J. O (2008): A Bivariate Analysis of Factors Affecting Rice Processing in Igbemo-Ekiti, Nigeria. Agricultural Journal, Vol 3, Issue 6, pg 442-446. Retrieved December 20, 2014 from http://medwelljournals.com/abstract/?doi=aj.2008.442.446

[7] Carney Judith A. 2001 Black Rice The African Origins of Rice Cultivation in the Americas. Cambridge, MA: Harvard University.

[8] Nitat Tangpinijkul 2010 Post-harvest Engineering Research Group Agricultural Engineering Research Institute Department of Agriculture, International Training Course on Post-harvest Technology and Processing of Agricultural Crops 14 November - 4 December 2010, Manhattan Klongluang Hotel, Pathum Thani, Thailand.

[9] ASTM. (1987). Standard Terminology Relating to Wear and Erosion. Annual Books of standard Vol 03.02, pp. 243-250.

[10] SAE International (2009): Chemical Compositions of SAE Alloy Steels J404_200901, Retrieved December 20, 2014 from https://www.sae.org/standards/content/j404_200901/ 